\title{
Left-sided omental infarction without torsion: report of a case with radiologic- pathologic correlation
}

\author{
Antonio Corvino ${ }^{1,2^{*}}$ (D), Maria Raffaela Campanino ${ }^{3}$, Nicolina De Rosa ${ }^{4}$, Fabio Corvino ${ }^{5}$ and Pietro Gisonni ${ }^{3}$
}

\begin{abstract}
Background: Omental infarction is a rare disease that affects the entire omentum or a segment of the greater omentum. It presents as acute abdominal pain mainly in the right lower quadrant or right flank. Left-sided omental torsion is infrequent and it is rarely preoperatively diagnosed. Omental infarction is a differential diagnosis in the acute abdomen. As most cases of omental infarction can be adequately diagnosed via computed tomography, a conservative treatment strategy for patients without complications should be considered in order to avoid any unnecessary surgical intervention.

Case presentation: We herein report a case of a surgically proved left-sided infarction of the greater omentum presenting with abdominal pain, tenderness of the left flank. Specifically, we describe the ultrasound (US) and computed tomography (CT) findings of this rare disease providing a radiological-pathological correlation of them. To date, there are few similar correlation reports in literature.

Conclusions: Although the classical treatment of omental infarction is surgery, more recently the conservative management has been suggested. Thus, we believe that the knowledge of the characteristic imaging findings is essential for establish a correct preoperative diagnosis, which can avoid unnecessary surgical intervention.
\end{abstract}

Keywords: Ultrasound, Contrast-enhanced computed tomography, Greater omentum, Omental infarction, Radiologic-pathologic correlation

\section{Background}

Omental infarction is a rare disease that affects the entire omentum or a segment of the greater omentum, the cause of which sometimes remains elusive $[1,2]$.

There have been about 300 cases of omental infarction reported in literature [3, 4] since the first case reported in 1896 by Bush [5]. Most of these are anecdotal case reports, just a few are case series describing the imaging appearance of omental infarcts, stillness are the radiologic-pathologic correlation articles.

\footnotetext{
* Correspondence: an.cor@hotmail.it

'Motor Science and Wellness Department, University of Naples "Parthenope", via F. Acton 38, I-80133 Naples, Italy

${ }^{2}$ Casal di Principe (CE), Italy

Full list of author information is available at the end of the article
}

In the past, an accurate diagnosis was rarely made before surgery. Recently, computed tomography (CT), mostly with the advent of multidetector-row technology, allows us to obtain typical, well recognizable, and reliable imaging features [6].

We herein report a case of a surgically proved leftsided infarction of the greater omentum presenting with abdominal pain, tenderness of the left flank. Specifically, we describe the ultrasound (US) and CT findings of this rare disease providing a radiological-pathological correlation of them.

Although the classical treatment of omental infarction is surgery, more recently the conservative management has been suggested. Thus, we believe that the knowledge of the characteristic imaging findings is essential for

\section{Springer Open}

(c) The Author(s). 2020 Open Access This article is licensed under a Creative Commons Attribution 4.0 International License, which permits use, sharing, adaptation, distribution and reproduction in any medium or format, as long as you give appropriate credit to the original author(s) and the source, provide a link to the Creative Commons licence, and indicate if changes were made. The images or other third party material in this article are included in the article's Creative Commons licence, unless indicated otherwise in a credit line to the material. If material is not included in the article's Creative Commons licence and your intended use is not permitted by statutory regulation or exceeds the permitted use, you will need to obtain permission directly from the copyright holder. To view a copy of this licence, visit http://creativecommons.org/licenses/by/4.0/. 
establish a correct preoperative diagnosis, which can avoid unnecessary surgical intervention $[7,8]$.

\section{Case presentation}

A 57-year-old Caucasian woman presented with a 5-day history of abdominal pain and nausea. The pain was severe, intermittent in nature, and was confined to the left upper quadrant (LUQ). Her past medical history was clear of any serious health problems. She did not consume alcohol and did not smoke.

She was on treatment with tibolone for over 24 months to treat perimenopausal symptoms. Specifically, she had been regularly taking tibolone $2.5 \mathrm{mg}$ daily for at least 12 months prior to this presentation. She was not on any other regular medication.

Physical examination revealed a fully alert patient with a soft and non-tender abdomen and normal bowel sounds. Pulse and blood pressure were normal ( 85 beats $/ \mathrm{min}, 123 / 83 \mathrm{mmHg}$ ). The remaining of the physical examination was unremarkable. Blood tests showed an elevated white blood cell count $(14.7 / \mathrm{nL})$ and serum C-reactive protein $(120 \mathrm{mg} / \mathrm{dL})$. A coagulation study (international normalized ratio, partial thromboplastin time, fibrinogen, and platelet count) revealed no abnormalities. Her chest X-ray was normal, plain abdominal films were free of any pathology, and electrocardiogram was normal.

Abdominal US (Fig. 1) was performed with a Philips iU22 xMATRIX US System scanner using multifrequency convex $(2.5-5 \mathrm{MHz})$ and linear $(7.5-12 \mathrm{Mhz})$ probes. US revealed an ovoid, non-compressible, hyperechoic lesion which contained avascular, poor-defined, hypoechoic linear areas. The lesion was located in the LUQ under the abdominal wall, exactly at level of the site of maximum tenderness.

To better assess the lesion, the patient was submitted to an abdomino-pelvic $\mathrm{CT}$ with a multidetector-row equipment (Aquilion 64, Toshiba, Japan). Bowel preparation was not performed. No orally or rectally administrable contrast medium was used. A frontal 512-mm scout view was first obtained with $120 \mathrm{kVp}$ and $50 \mathrm{~mA}$. This was followed by helical scanning from the top of the liver to the symphysis pubis with the following scanning parameters: detector configuration $=1 \times 32 \mathrm{~mm}$, table feed $36 \mathrm{~mm} \mathrm{~s}^{-1}$, rotation time $=0.75 \mathrm{~s}$, helical pitch $=27$, section thickness $=5 \mathrm{~mm}, 120 \mathrm{kVp}$, and automated

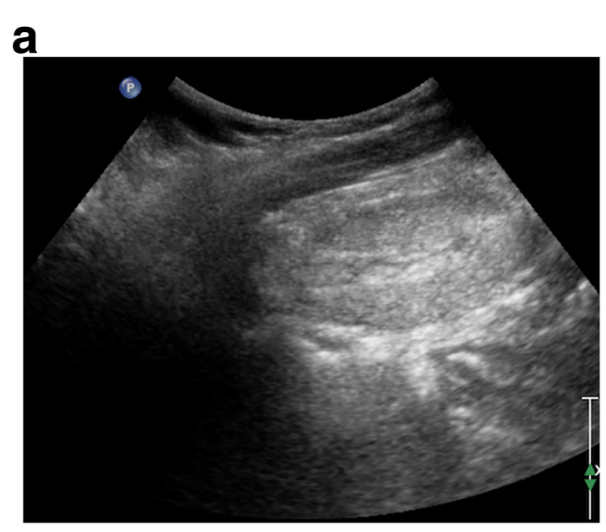

b

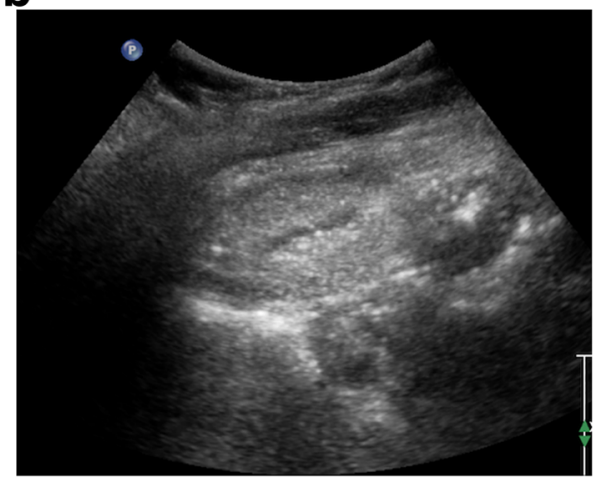

C

d
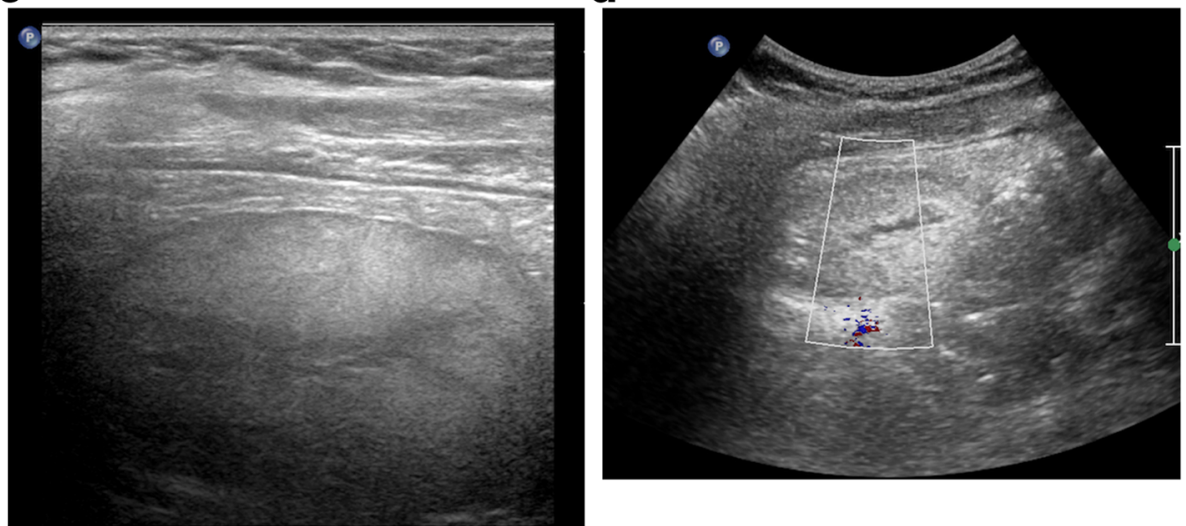

Fig. 1 Transverse gray-scale US sonograms obtained using a multifrequency convex (2.5-5 MHz) (a, b) and linear probes (7.5-12 MHz) (c) show an ovoid, hyperechoic lesion next to anterior abdominal wall in left upper abdominal quadrant which contained avascular, poor-defined, hypoechoic linear areas. d Color Doppler sonogram shows complete absence of Doppler signal within the mass 
tube current modulation. From the raw data of the acquisition, 3-mm-thick transverse sections were reconstructed with $1.5-\mathrm{mm}$ increments. Arterial, portal, and late phase acquisitions were performed with fix scan delays of 35,80 , and $180 \mathrm{~s}$ after iv bolus injection $(2,5 \mathrm{cc} / \mathrm{s})$ of $120 \mathrm{cc}$ of nonionic iodinated contrast media (Iopamiro $370 \mathrm{mgI} \mathrm{m}{ }^{-1}$ Bracco Imaging, Milan, Italy) followed by $200 \mathrm{cc}$ of saline solution with a dual-head injector (Stellant Injection System, Medrad Inc., USA).

Contrast-enhanced CT (Fig. 2) showed an encapsulated mass of fat density with internal soft-tissue attenuation streaks located directly under the abdominal wall, below the splenic flexure of the colon. The wall of the colon was not thickened and adjacent small bowel was only slightly displaced. The radiologic diagnosis was consistent with omental infarction.

Upon patient's decision, a surgical exploration was performed which identified a large inflammatory omental mass consisting of a section of infarcted omentum. An omental flap of $11 \times 8 \times 6 \mathrm{~cm}$ including the lesion was removed. The large and small bowel were normal and intact. On further exploration, no adhesions or other underlying causes for omental infarction, such as an external or internal hernia or a vascular pedicle, were noted.

Gross examination of specimens revealed small areas suggestive of hemorragic infarction and fat necrosis interspersed with omental parenchyma with edema and vascular congestion. Microscopic examination showed areas of hemorrhage with acute and chronic inflammatory cell infiltrate, ischemic, and fat necrosis surrounded by edematous and congested omental tissue. The arterial and venous vessels were dilated and congested with venous thrombosis (Fig. 3). The radiologic-pathologic correlation revealed that the streaks within the mass corresponded to tissue with hemorrhage and necrosis within a congested omental tissue. Finally, a pathological diagnosis of omental infarction was made. The patient had a successful recovery postoperatively without complications and was discharged home 4 days after the procedure.

\section{Discussion}

The greater omentum is a large peritoneal fold that is continuous with the visceral peritoneal layers of the stomach and transverse colon. It contains fat and blood vessels and often serves to contain the spread of intraperitoneal infections [6].

Torsion of the omentum is the main reason for infarction and two different forms have been described: primary torsions (without other pathologic intra-abdominal findings) and secondary torsions (tumors, cysts, inflammatory changes, adhesions, hernias). Predisposing factors for torsion are anomalies of the omentum, such as a small root, irregular vascular anatomy, abdominal trauma, cough, and physical strain $[7,8]$.

The etiology of omental infarction without torsion remains uncertain but several mechanisms have been proposed, such as an anomaly of venous vessels. Other possible causes for primary infarctions could be disorders of hemostasis or vascular diseases. It is known that hematologic changes occur during pregnancy and the puerperium and that hypercoagulability leads to an increased risk of thromboembolic events. The exact mechanism leading to infarction in this case remains unclear [9-11].

Our patient was on treatment with tibolone for over 24 months to treat perimenopausal symptoms. However, data of the effects of tibolone on the coagulatory system as well as the risk of venous thromboembolism in postmenopausal women are not univocal $[12,13]$. Therefore, unless future studies, in our case tibolone seems to be not involved.

Both primary and secondary omental infarction, with or without torsion, result in venous stasis and thrombosis leading to congestion and edema, pathologically

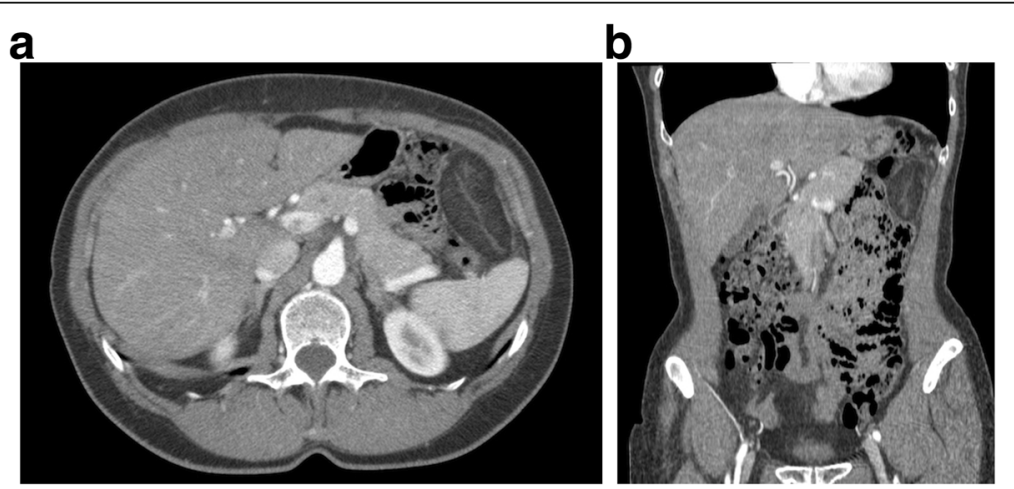

Fig. 2 Axial (a) and coronal (b) contrast-enhanced CT scans of the abdomen showed an encapsulated mass of fat density with internal soft-tissue attenuation streaks located directly under the abdominal wall, below the splenic flexure of the colon (Fig. 1). The wall of the colon was not thickened and adjacent small bowel was only slightly displaced 
a

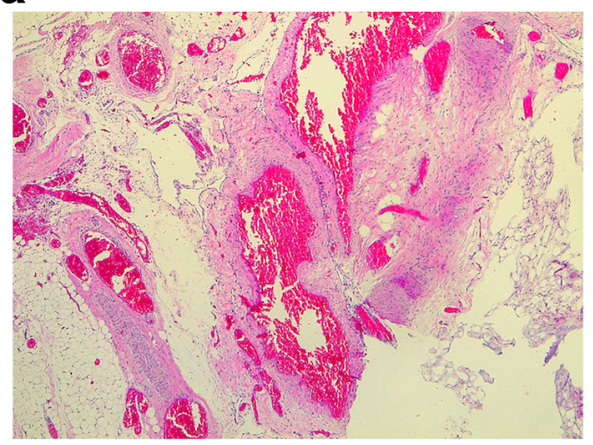

C

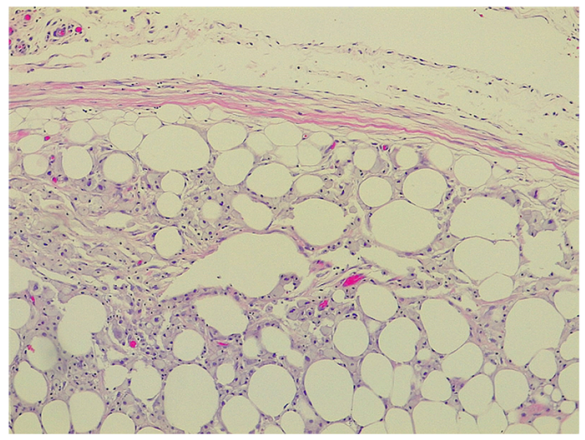

b

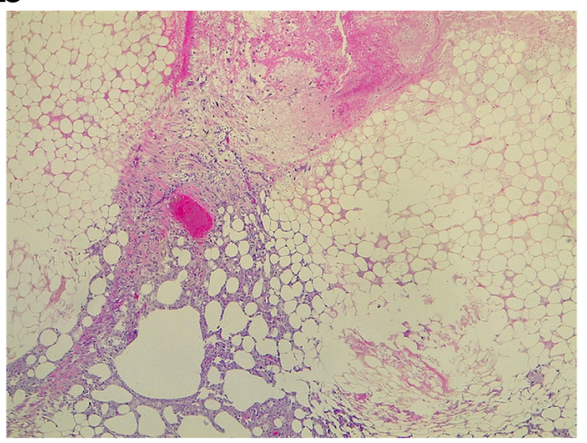

d

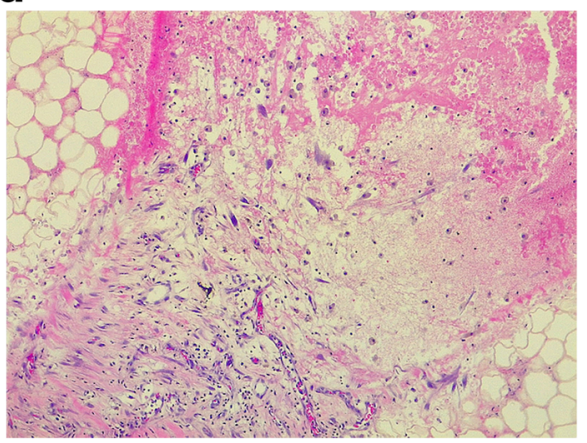

Fig. 3 Pathology photomicrographs, hematoxylin/eosin-stained $\times 4$ magnification $(\mathbf{a}, \mathbf{b})$ and $\times 20$ magnification (c, $\mathbf{d})$, show congested vessels, acute and chronic inflammatory cell infiltrate, hemorrhage, focal ischemic and fat necrosis, and fibrinous exudates

with hemorrhagic necrosis and extravasation of serosanguineous peritoneal fluid. In our patient, no obvious anatomic and pathologic reasons or precipitating factors for the omental infarction were found, so we were dealing with a case of omental infarction without torsion $[10,11]$.

The great majority of cases of omental infarction reported in the literature were segmental involving the right side of the omentum with right lower quadrant or right para-umbilical pain mimicking perforated duodenal ulcer, acute appendicitis, acute cholecystitis, cecal diverticulitis or epiploic appendagitis $[1,2]$. Left-sided omental infarction is unusual but has been described [14].

Since the great majority of patients present with acute abdomen, a CT scan of the abdomen is the examination of choice and can assist in the exclusion of various other conditions presenting a similar clinical setting. However, the incidence of omental infarction is low and the clinical features often non-specific; thus, it is not included in the clinical differential diagnosis in most of cases on initial evaluation $[1,2]$.

By showing CT findings suggestive of diverticulitis such as visualization of the inflamed diverticulum, marked wall thickening, and formation of paracolic abscess, the CT scan will help in narrowing the differential diagnosis. In fact, in omental infarction there is no or only subtle local wall thickening, although a case of omental torsion with transient thickening of the wall of the transverse colon has been recently reported $[6,7]$.

Differentiating appendagitis from omental torsion is more subtle. Thickening of the adjacent bowel wall is not a constant feature of primary epiploic appendagitis. However, the larger size and the location of the mass relative to the ascending or descending colon favor omental abnormality rather than primary epiploic appendagitis $[15,16]$.

The CT findings of fatty mass in the omentum may also suggest other diagnoses including lipoma, liposarcoma, angiomyolipoma, teratoma, mesenteric lipodystrophy, pseudomyxoma peritonii, and peritoneal mesothelioma or metastatic peritoneal seeding (commonly from ovarian cancer). All of these conditions clearly present in a different clinical setting so that diagnostic confusion is unlikely [17-20].

CT findings of omental infarction without torsions, as in our case, include a well circumscribed, oval, or cakelike fatty mass with heterogeneous attenuation, containing strands of soft-tissue attenuation corresponding to hemorrhage and necrosis. Focal fat stranding surrounding the lesion is often associated. The mass is most often located deep to the rectus abdominis and anterior to the colon. It appears adherent to inflamed, thickened 
parietal peritoneum. A small to moderate amount of free peritoneal fluid may be present [21, 22].

In these cases, gross pathologic examination reveals the presence of an omental mass with areas of hemorrhagic infarction. The earliest microscopic finding is hemorrhagic infarction; later, varying degrees of inflammatory infiltrate are seen. The most advanced stage is characterized by the presence of a fibroblastic reaction [11].

The importance of making the correct CT diagnosis of acute omental infarction is especially important to avoid unnecessary surgical intervention. Traditionally, surgery has been the treatment of choice. Nevertheless, most recent literature shows a disunity between authors regarding the designated treatment. Arguments in favor of conservative medical management are the often selfresolving character of omental infarction, especially since omental infarction is described to be self-limiting (proven with CT) even after 1-3 years follow-up, as well as the safety and effectiveness of conservative treatment, which protects patients from unnecessary surgical intervention. Arguments in favor of surgical intervention are a shorter length of hospitalization time compared with conservative treatment, which save money. In addition, (laparoscopic) treatment is favored by some because it allows for confirmation of the radiologic findings [23].

Thus, a conservative initial approach seems justified, but it should be done with caution and followed up by clinical and imaging evaluation until complete resolution occurs. Intervention is required when the patient's condition worsens or when there are doubts on the diagnosis $[1,2]$.

\section{Conclusions}

Omental infarction is a rare cause of acute abdominal pain and can be diagnosed preoperatively on CT when a fatty mass is seen in the greater omentum. The disease occurs occasionally on the left side of the abdomen. Conservative management can be safety adopted in the absence of complications. Only in uncommon circumstances of unclear imaging findings or deterioration in the patient's conditions, a diagnostic laparoscopy as a minimal invasive approach may settle the diagnosis and can be extended to a therapeutic maneuver.

\section{Abbreviations}

CT: Computed tomography; US: Ultrasound; LUQ: Left upper quadrant

\section{Acknowledgements}

No acknowledgements are present.

\section{Authors' contributions}

AC made substantial contributions to the design of the work; acquisition, analysis, and interpretation of data; drafted the work and revised it; and approved the submitted version and agreed both to be personally accountable for the author's own contributions and to ensure that questions related to the accuracy or integrity of any part of the work, even ones in which the author was not personally involved, are appropriately investigated, resolved, and the resolution documented in the literature. MRC made acquisition, analysis, and interpretation of data and approved the submitted version and agreed both to be personally accountable for the author's own contributions and to ensure that questions related to the accuracy or integrity of any part of the work, even ones in which the author was not personally involved, are appropriately investigated, resolved, and the resolution documented in the literature. DRN made acquisition, analysis, and interpretation of data and approved the submitted version and agreed both to be personally accountable for the author's own contributions and to ensure that questions related to the accuracy or integrity of any part of the work, even ones in which the author was not personally involved, are appropriately investigated, resolved, and the resolution documented in the literature. FC drafted the work and revised it and approved the submitted version and agreed both to be personally accountable for the author's own contributions and to ensure that questions related to the accuracy or integrity of any part of the work, even ones in which the author was not personally involved, are appropriately investigated, resolved, and the resolution documented in the literature. PG made acquisition, analysis, and interpretation of data and approved the submitted version and agreed both to be personally accountable for the author's own contributions and to ensure that questions related to the accuracy or integrity of any part of the work, even ones in which the author was not personally involved, are appropriately investigated, resolved, and the resolution documented in the literature. Each author has participated sufficiently in any submission to take public responsibility for its content. All authors have read and approved the manuscript. We confirm that this work is original and has not been published elsewhere nor it is currently under consideration for publication elsewhere.

\section{Funding}

No research funding was obtained.

Availability of data and materials

The datasets used and/or analyzed in the report are available from the corresponding author on reasonable request.

\section{Ethics approval and consent to participate}

The research involving human participants was approved by the ethics committee of the institutions involved (Parthenope University of Naples, University Federico II of Naples, Monaldi Hospital - AORN Ospedali dei Colli) and written informed consent was obtained to participate.

\section{Consent for publication}

Written informed consent for publication was obtained from the patient.

\section{Competing interests}

The authors have no conflicts of interest.

\section{Author details}

'Motor Science and Wellness Department, University of Naples "Parthenope", via F. Acton 38, I-80133 Naples, Italy. ${ }^{2}$ Casal di Principe (CE), Italy. ${ }^{3}$ Advanced Biomedical Sciences Department, University Federico II of Naples (UNINA), via S. Pansini 5, I-80131 Naples, Italy. ${ }^{4}$ Pathology Department, Monaldi Hospital - AORN Ospedali dei Colli, via Leonardo Bianchi, I-80131 Naples, Italy. ${ }^{5}$ Vascular and Interventional Radiology Department, Cardarelli Hospital, via A. Cardarelli 9, I-80131 Naples, Italy.

Received: 17 April 2020 Accepted: 26 June 2020

Published online: 07 July 2020

References

1. Aoun N, Haddad-Zebouni S, Slaba S, Noun R, Ghossain M (2001). Left-sided omental torsion: CT appearance. Eur Radiol 11(1):96-98.

2. Singh AK, Gervais DA, Lee P, Westra S, Hahn PF, Novelline RA, Mueller PR (2006) Omental infarct: CT imaging features. Abdom Imaging 31(5):549-554 Epub 2006 Feb 7

3. Tachezy M, Grotelüschen R, Gebauer F, Marx AH, Izbicki JR, Kaifi JT (2010) Omental infarction in the postpartum period: a case report and a review of the literature. J Med Case Rep 4:368. https://doi.org/10. 1186/1752-1947-4-368 
4. Naffaa LN, Shabb NS, Haddad MC (2003) CT findings of omental torsion and infarction: case report and review of the literature. Clin Imaging 27(2):116-118

5. Balthazar EJ, Lefkowitz RA (1993) Left-sided omental infarction with associated omental abscess: CT diagnosis. J Comput Assist Tomogr 17(3):379-381

6. Kamaya A, Federle MP, Desser TS (2011) Imaging manifestations of abdominal fat necrosis and its mimics. Radiographics 31(7):2021-2034. https://doi.org/10.1148/rg.317115046

7. Cianci R, Filippone A, Basilico R, Storto ML (2008) Idiopathic segmental infarction of the greater omentum diagnosed by unenhanced multidetector-row CT and treated successfully by laparoscopy. Emerg Radiol 15(1):51-56 Epub 2007 Jul 3

8. Buell KG, Burke-Smith A, Patel V, Watfah J (2017) Omental infarction: the great impersonator. Cureus 9(12):e1940. https://doi.org/10.7759/cureus.1940

9. Devos H, Goethals L, Belsack D, Brucker Y, Allemeersch GJ, Ilsen B, Vandenbroucke F, de Mey J (2020) Fat misbehaving in the abdominal cavity: a pictorial essay. Pol J Radiol 85:e32-e38. https://doi.org/10.5114/pjr. 2020.93070 eCollection 2020

10. Walia R, Verma R, Copeland N, Goubeaux D, Pabby S, Khan R (2014) Omental infarction: an unusual cause of left-sided abdominal pain. ACG Case Rep J 1(4): 223-224. https://doi.org/10.14309/crj.2014.60 eCollection 2014 Jul

11. Baldisserotto M, Maffazzoni DR, Dora MD (2005) Omental infarction in children: color Doppler sonography correlated with surgery and pathology findings. AJR Am J Roentgenol 184(1):156-162

12. Biglia N, Maffei S, Lello S, Nappi RE (2010) Tibolone in postmenopausal women: a review based on recent randomised controlled clinical trials. Gynecol Endocrinol 26(11):804-814. https://doi.org/10.3109/09513590.2010.495437

13. Cummings SR, Ettinger B, Delmas PD, Kenemans P, Stathopoulos V, Verweij P, Mol-Arts M, Kloosterboer L, Mosca L, Christiansen C, Bilezikian J, Kerzberg EM, Johnson S, Zanchetta J, Grobbee DE, Seifert W, Eastell R, LIFT Trial Investigators (2008) The effects of tibolone in older postmenopausal women. N Engl J Med 359(7):697-708. https://doi.org/10.1056/ NEJMoa0800743

14. Yager A, Carmeci C (1999) Torsion of the greater omentum: CT findings. AJR Am J Roentgenol 173(4):1139-1140

15. Corvino A, Rosa D, Sbordone C, Nunziata A, Corvino F, Varelli C, Catalano O (2019) Diastasis of rectus abdominis muscles: patterns of anatomical variation as demonstrated by ultrasound. Pol J Radiol 84:e542-e548. https:// doi.org/10.5114/pjr.2019.91303 eCollection 2019

16. Corvino A, Corvino F, Radice L, Catalano O (2015) Synchronous mucinous colonic adenocarcinoma and multiple small intestinal adenocarcinomas: report of a case and review of literature. Clin Imaging 39(3):538-542. https:// doi.org/10.1016/j.clinimag.2014.12.019 Epub 2015 Jan 7

17. Levy AD, Rimola J, Mehrotra AK, Sobin LH (2006) From the archives of the AFIP: benign fibrous tumors and tumorlike lesions of the mesentery: radiologic-pathologic correlation. Radiographics 26(1):245-264

18. Sheth S, Horton KM, Garland MR, Fishman EK (2003) Mesenteric neoplasms: $\mathrm{CT}$ appearances of primary and secondary tumors and differential diagnosis. Radiographics 23(2):457-473 quiz 535-6

19. Levy AD, Shaw JC, Sobin LH (2009) Secondary tumors and tumorlike lesions of the peritoneal cavity: imaging features with pathologic correlation. Radiographics 29(2):347-373. https://doi.org/10.1148/rg.292085189

20. Corvino A, Pignata S, Campanino MR, Corvino F, Giurazza F, Tafuri D, Pinto F, Catalano O (2020). Thyroglossal duct cysts and site-specific differential diagnoses: imaging findings with emphasis on ultrasound assessment. J Ultrasound 2020 Feb 12. doi: https://doi.org/10.1007/s40477-020-00433-2. [Epub ahead of print].

21. Puylaert JB (1992) Right-sided segmental infarction of the omentum: clinical, US, and CT findings. Radiology 185(1):169-172

22. van Breda Vriesman AC, Lohle PN, Coerkamp EG, Puylaert JB (1999) Infarction of omentum and epiploic appendage: diagnosis, epidemiology and natural history. Eur Radiol 9(9):1886-1892

23. Nijkamp JLG, Gerretsen SC, Stassen PM (2018) Left-sided omental infarction: a rare cause of abdominal pain, discovered by CT scan. BMJ case rep 2018. Pii: bcr-2017-224138. https://doi.org/10.1136/bcr-2017-224138

\section{Publisher's Note}

Springer Nature remains neutral with regard to jurisdictional claims in published maps and institutional affiliations.

\section{Submit your manuscript to a SpringerOpen ${ }^{\circ}$ journal and benefit from:}

- Convenient online submission

- Rigorous peer review

- Open access: articles freely available online

High visibility within the field

- Retaining the copyright to your article

Submit your next manuscript at $\boldsymbol{\nabla}$ springeropen.com 